\title{
Editorial
}

\section{Alles auf Anfang}

_ Wussten Sie, dass der gute „Rutsch“ ins neue Jahr gar nichts mit Glatteis zu tun hat? Stattdessen kommt der „rosch“ aus dem Hebräischen und bedeutet „Anfang“. Man wünscht sich also einfach einen guten Jahresanfang. Und schon ergibt das Ganze wieder Sinn.

_ Konnten Sie das alte Jahr guten Gewissens ausklingen lassen und das neue zuversichtlich beginnen? Vielleicht mit dem einen oder anderen guten Vorsatz? Ich habe mir vor einem Jahr ganz klassisch vorgenommen, mehr Sport zu treiben. Heute kann ich sagen: „Geschafft!“ Ich habe mich tatsächlich im Fitnessstudio angemeldet und strample mich seitdem regelmäßig $a b$. Bekämpft habe ich meinen inneren Schweinehund, indem ich mir einen Anreiz für eine Bikinifigur geschaffen und gleichzeitig einen Traum erfüllt habe: Urlaub auf den Malediven. Der ist jetzt schon fast ein Dreivierteljahr her, und mein Sportpensum hat sich von drei- auf zweimal die Woche verringert. Ich sollte schleunigst den nächsten Flug in die Sonne buchen!

_ Der Mensch braucht also Belohnung, um unangenehme Dinge anzupacken und sie nicht auf die lange Bank zu schieben. Was genau hinter diesem weit verbreiteten Phänomen steckt und wann sich die sogenannte Prokrastination zu einer echten Arbeitsstörung entwickelt, lesen Sie auf Seite 29. Vielleicht überdenken Sie danach Ihre guten Vorsätze, gehen sie effektiver an und kümmern sich beispielsweise um Ihre Rente. Anregungen dazu finden Sie auf Seite 10.

_ Was 2011 wohl alles bringen wird? Einen neuen Arbeitsplatz, eine Hochzeit, einen runden Geburtstag, ...? Einige Eckdaten kennen wir bereits. Zum Beispiel, dass uns das neue Jahr viele Brückentage und die FIFA-FrauenWeltmeisterschaft in Deutschland bescheren wird. Füllen wir diese Ereignisse in den nächsten 365 Tagen mit Leben und Erinnerungen.

In diesem Sinne wünsche ich ergopraxis und Ihnen ein gesundes, lebendiges und unvergessliches neues Jahr! Packen wir es an und machen den Anfang.

Ihre

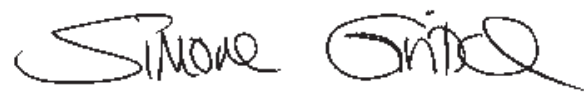

\section{ZU GEWINNEN}

Kursplatz

1 Kurs

„Praxis für die Praxis“ Seite 45

Bücher

1-mal

„Private Altersvorsorge“ Seite 12

2-mal „ADHS im

Erwachsenenalter“

Seite 23

Und außerdem...

2 Geschenksets

"Zengarten \& Tee“

Seite 27

3 Entscheidungswürfelsets Seite 30 